\title{
Severity prediction rules in community acquired pneumonia: a validation study
}

\author{
W S Lim, S Lewis, J T Macfarlane
}

\begin{abstract}
Background-The British Thoracic Society (BTS) developed a rule (BTSr) based on severity criteria to predict short term mortality in adults admitted to hospital with community acquired pneumonia (CAP). However, neither the BTSr nor a recent modification of it (mBTSr) have been validated in the UK. A case-control study was conducted in a typical UK population to determine the clinical factors predictive of mortality and to assess the performance of these rules.

Methods-Cases were drawn from all patients with CAP who died in 1997 in five large hospitals in the Mid Trent area. Controls were randomly selected from survivors. Factors associated with mortality were identified following review of medical case notes and performance of the severity prediction rules assessed.

Results-Age $>65$ years, temperature $<37^{\circ} \mathrm{C}$, respiratory rate $>24$ breaths/min, mental confusion, urea concentration of $>7 \mathrm{mmol} / \mathrm{l}$, sodium concentration of $<135 \mathrm{mmol} / \mathrm{l}$, and the presence of a pleural effusion, all determined on admission, were independently associated with inhospital mortality on multivariate analysis. The BTSr was $52 \%$ sensitive and $79 \%$ specific in predicting death while the mBTSr displayed $66 \%$ sensitivity and $73 \%$ specificity.

Conclusions-The value of three of the four factors (presence of mental confusion, raised respiratory rate, raised urea) used in the mBTSr as predictors of mortality is confirmed. However, the BTSr and mBTSr did not perform as well in this validation study which included a high proportion $(48 \%)$ of elderly patients ( $\geqslant 75$ years) compared with the derivation studies.

(Thorax 2000;55:219-223)
\end{abstract}

Respiratory Medicine, City Hospital,

Nottingham NG5 1PB, UK

W S Lim

$S$ Lewis

J T Macfarlane

Correspondence to Dr J T Macfarlane

Received 24 August 1999 Returned to authors 8 November 1999

Revised manuscript received

30 November 1999

Accepted for publication

1 December 1999
Keywords: community acquired pneumonia; prediction rule; severity

Community acquired pneumonia (CAP) is common. In the UK it results in about 83000 admissions to hospital each year and is the fourth leading cause of death. ${ }^{1}$ Management is crucially dependent on an accurate and early assessment of disease severity. In 1987 the British Thoracic Society (BTS) derived a rule (BTSr) based on three easily measured clinical parameters for predicting patients who had a 21 -fold increased risk of death. ${ }^{2}$ Other prediction rules published since then include a modi- fied BTS rule (mBTSr) which increases the sensitivity of the original rule at the expense of specificity. ${ }^{3}$ In the USA a pneumonia severity index (PSI) for the stratification of patients with CAP into risk classes based on mortality has also been widely studied. ${ }^{4}$

Integral to the development of a clinical prediction rule is the demonstration of validity in a separate cohort of patients from the derivation group. ${ }^{5}$ The adoption of a prediction rule into clinical practice requires that the rule be shown to be "transportable" into the appropriate clinical setting, both geographically and practically. ${ }^{6}$ Surprisingly, neither the BTSr, mBTSr nor the PSI have ever been validated in the UK.

The aims of this case-control study were to identify the clinical factors independently predictive of mortality, to determine the appropriate cut off values for any continuous variables thus identified, and to validate the BTSr and $\mathrm{mBTSr}$ in a UK population, comparing the performance of these rules with the North American PSI.

\section{Methods}

Adults aged over 16 years admitted to any of the five acute hospitals in the Mid Trent region of the UK (Nottingham City Hospital, University Hospital Nottingham, Derbyshire Royal Infirmary, Derby City General Hospital and King's Mill Hospital, Mansfield) between 1 January 1997 and 31 December 1997 with a diagnosis of pneumonia were identified from computer records. Cases were defined as patients who died during hospital admission. An equal number of controls was drawn randomly from the remaining patients. In the case of multiple admissions within the study period, only the first hospital admission was studied.

Medical case notes of cases and controls were reviewed to confirm the diagnosis of CAP. The inclusion and exclusion criteria were based on those used in the original BTS study. There was no upper age limit. CAP was defined by the presence of shadowing on an admission chest radiograph consistent with infection, inpatient treatment for pneumonia, and a discharge diagnosis of pneumonia. Patients discharged from hospital in the last 10 days were excluded as were patients with tuberculosis, lung cancer, and HIV. Immunocompromised patients (those with neutropenia or on chemotherapy) were also excluded. Treatment with oral steroids was not a cause for exclusion.

Patient demographic features were recorded according to a standard questionnaire. Data for pulse, blood pressure, respiratory rate, the 
Table 1 Demographic features of 122 cases and 122 controls

\begin{tabular}{|c|c|c|c|c|}
\hline & \multirow{2}{*}{$\begin{array}{l}\text { No. with } \\
\text { complete data }\end{array}$} & Cases & Controls & \multirow[b]{2}{*}{$p$ valuet } \\
\hline & & No. $(\%)$ & No. $(\%)$ & \\
\hline Male & 244 & $68(56)$ & $59(48)$ & 0.32 \\
\hline $\begin{array}{l}\text { Admitted from nursing/residential } \\
\text { home }\end{array}$ & 244 & $32(26)$ & $7(6)$ & $<0.01^{\star}$ \\
\hline Prior antibiotics & 244 & $38(31)$ & $32(26)$ & 0.09 \\
\hline \multicolumn{5}{|l|}{ Comorbid conditions: } \\
\hline Cancer & 243 & $18(15)$ & $4(3)$ & 0.068 \\
\hline Congestive cardiac failure & 244 & $11(9)$ & $6(5)$ & 0.97 \\
\hline COPD & 244 & $14(11)$ & $8(7)$ & 0.99 \\
\hline CVA/TIA & 244 & $13(11)$ & $8(7)$ & 0.69 \\
\hline Ischaemic heart disease & 244 & $26(21)$ & $10(8.2)$ & 0.13 \\
\hline None & 244 & $20(16)$ & $47(39)$ & 0.39 \\
\hline
\end{tabular}

COPD $=$ chronic obstructive pulmonary disease: CVA = cerebrovascular accident; TIA = transient ischaemic attack.

${ }^{\star} \mathrm{p}<0.05 ; \mathrm{tp}$ value adjusted for age.

Table 2 Association of clinical features with mortality on univariate analysis

\begin{tabular}{|c|c|c|c|c|}
\hline & $\begin{array}{l}\text { No. with } \\
\text { complete data }\end{array}$ & $\begin{array}{l}\text { Age adjusted odds } \\
\text { ratio }\end{array}$ & $C I$ & pvalue \\
\hline Age (years) & 244 & (unadjusted) & & \\
\hline$\leqslant 51$ & & - & & $<0.001$ \\
\hline $52-74$ & & 5.69 & 2.39 to 13.55 & \\
\hline $75-84$ & & 17.29 & 6.98 to 42.78 & \\
\hline$\geqslant 85$ & & 8.82 & 3.67 to 21.18 & \\
\hline Temperature $\left({ }^{\circ} \mathrm{C}\right)$ & 242 & & & \\
\hline$\geqslant 38.1$ & & - & & $0.001^{\star}$ \\
\hline $37.1-38.0$ & & 1.66 & 0.71 to 3.87 & \\
\hline $36.3-37.0$ & & 3.50 & 1.50 to 8.19 & \\
\hline$\leqslant 36.2$ & & 4.88 & 2.04 to 11.65 & \\
\hline Pulse (beats/min) & 244 & & & \\
\hline$\leqslant 82$ & & - & & 0.17 \\
\hline $83-100$ & & 1.84 & 0.88 to 3.86 & \\
\hline $101-110$ & & 1.43 & 0.52 to 4.00 & \\
\hline$\geqslant 111$ & & 2.48 & 1.08 to 5.66 & \\
\hline $\begin{array}{l}\text { Systolic blood pressure } \\
(\mathrm{mm} \mathrm{Hg})\end{array}$ & 243 & & & \\
\hline$\geqslant 141$ & & - & & 0.47 \\
\hline $131-140$ & & 1.07 & 0.44 to 2.61 & \\
\hline $111-130$ & & 1.03 & 0.48 to 2.19 & \\
\hline$\leqslant 110$ & & 1.76 & 0.78 to 3.97 & \\
\hline $\begin{array}{l}\text { Diastolic blood pressure } \\
(\mathrm{mm} \mathrm{Hg})\end{array}$ & 243 & & & \\
\hline$\geqslant 81$ & & - & & 0.07 \\
\hline $71-80$ & & 0.65 & 0.27 to 1.55 & \\
\hline $61-70$ & & 0.81 & 0.34 to 1.94 & \\
\hline$\leqslant 60$ & & 1.81 & 0.74 to 4.42 & \\
\hline Respiratory rate (/min) & 196 & & & \\
\hline$\leqslant 20$ & & - & & $0.04^{\star}$ \\
\hline $21-24$ & & 1.34 & 0.54 to 3.39 & \\
\hline $25-30$ & & 3.09 & 1.29 to 7.38 & \\
\hline$\geqslant 31$ & & 2.56 & 1.06 to 6.18 & \\
\hline Mental confusion & 243 & 4.62 & 2.26 to 9.47 & $<0.001^{\star}$ \\
\hline
\end{tabular}

presence of confusion, and oxygen saturation on hospital admission were taken as the first recorded values within 24 hours of admission. Mental status was taken to be normal unless otherwise recorded. Only results of investigations performed within 24 hours of admission were studied. These included haemoglobin, white cell count, platelet count, haematocrit, urea, creatinine, sodium, potassium, alkaline phosphatase, liver enzymes, albumin, pulse oximetry, and blood gas tensions. Initial antibiotic therapy was recorded.

Details of choice of initial antibiotic(s) and route of administration were noted as were the pathogens identified by routine microbiological investigations. The primary outcome measure was in-hospital mortality.

STATISTICAL ANALYSIS

Data were analysed using SPSS Version 8.0 for Windows. Twenty six variables were examined for association with mortality. Most were con- tinuously distributed and, to avoid any assumptions regarding the form of the relationship of these variables to mortality, each was initially re-expressed as four level factors using quartile cut offs. The univariate association of each of the resultant variables with mortality was analysed by logistic regression, with and without adjustment for age as the most likely confounder. Statistical significance was assessed by testing for a difference in odds (binary variables) or a trend in odds across categories (categorical variables).

Variables which were significantly $(\mathrm{p}<0.05)$ related to mortality in univariate analysis were entered simultaneously into a multiple logistic regression. Continuous variables were initially entered as four level factors and the independent significance of each was tested as before. Those which remained significant in multivariate analysis were re-categorised into binary factors, if appropriate, using threshold values determined by examination of the multivariate odds ratios. Where the threshold value suggested by our analyses differed from those implicit in one or more of the existing severity criteria, the effect of changing the threshold was investigated. All remaining variables were then tested, one at a time, to confirm their contribution to the multivariate model. Results of multivariate analysis are reported as odds ratios with $95 \%$ confidence intervals and $\mathrm{p}$ values, taking $\mathrm{p}<0.05$ as the level of statistical significance.

The sensitivities, specificities, positive predictive values, and negative predictive values of the BTS rule and modified BTS rule were calculated and compared. The effect of age on the performance of these rules was also examined. The PSI was calculated for all patients. Missing values required for the computation of the PSI but which are not routinely performed in all hospitals in the UK were taken to be normal. These included albumin, glucose, $\mathrm{pH}$ and $\mathrm{Po}_{2}$ (unless oxygen saturation was independently documented as $<90 \%$ ). The predictive value of the highest risk class of the PSI was compared with the BTS and modified BTS rules.

\section{Results}

During the 12 month study period 1253 patients with a primary discharge diagnosis of pneumonia were identified from computer records at the five study hospitals. There were 181 patients who died during hospital admission. Of these, $122(67 \%)$ patients satisfied the study criteria for CAP. A random sample of 181 patients was drawn from the remaining patients stratified by hospital site. Examination of medical records of the first 171 patients yielded 122 controls (71\%) satisfying the study inclusion criteria. Patients excluded comprised those who did not have radiographically confirmed pneumonia and those who had nosocomial pneumonia.

The mean age of cases was 76 years (range 19-98) compared with 59 years (range 18-97) in controls $(\mathrm{p}<0.001)$.

Initial antimicrobial therapy was given intravenously in $99(81 \%)$ cases and $86(70 \%)$ controls. There was no difference in the proportion 
Table 3 Association of initial investigations with mortality on univariate analysis

\begin{tabular}{|c|c|c|c|c|}
\hline & $\begin{array}{l}\text { No. with } \\
\text { complete data }\end{array}$ & $\begin{array}{l}\text { Age adjusted } \\
\text { odds ratio }\end{array}$ & $C I$ & $p$ value \\
\hline Haemoglobin (g/dl) & 232 & & & \\
\hline$\geqslant 14.0$ & & - & & $0.046^{\star}$ \\
\hline $12.7-13.9$ & & 0.61 & 0.26 to 1.40 & \\
\hline $11.3-12.6$ & & 0.88 & 0.40 to 1.94 & \\
\hline$\leqslant 11.2$ & & 2.09 & 0.89 to 4.88 & \\
\hline Haemotocrit (1/1) & 179 & & & \\
\hline$\geqslant 0.421$ & & - & & 0.10 \\
\hline $0.382-0.420$ & & 0.48 & 0.18 to 1.25 & \\
\hline $0.343-0.381$ & & 0.58 & 0.22 to 1.50 & \\
\hline$\leqslant 0.342$ & & 1.37 & 0.52 to 3.65 & \\
\hline White cell count $\left(\times 10^{9} / 1\right)$ & 237 & & & \\
\hline$\leqslant 8.21$ & & - & & 0.66 \\
\hline $8.22-12.60$ & & 1.18 & 0.52 to 2.67 & \\
\hline $12.61-16.72$ & & 0.76 & 0.34 to 1.69 & \\
\hline$\geqslant 16.73$ & & 1.21 & 0.53 to 2.75 & \\
\hline $\mathrm{PaO}_{2}(\mathrm{kPa})$ & 137 & & & \\
\hline$\geqslant 10.3$ & & - & & 0.29 \\
\hline $8.4-10.2$ & & 0.36 & 0.12 to 1.09 & \\
\hline $7.3-8.3$ & & 0.74 & 0.24 to 2.24 & \\
\hline$\leqslant 7.2$ & & 0.50 & 0.16 to 1.56 & \\
\hline Sodium $(\mathrm{mmol} / \mathrm{l})$ & 237 & & & \\
\hline$\geqslant 141$ & & - & & $0.0045^{\star}$ \\
\hline $138-140$ & & 0.31 & 0.12 to 0.78 & \\
\hline $135-137$ & & 0.17 & 0.06 to 0.46 & \\
\hline$\leqslant 134$ & & 0.45 & 0.18 to 1.10 & \\
\hline Urea $(\mathrm{mmol} / \mathrm{l})$ & 237 & & & \\
\hline$\leqslant 5.3$ & & - & & $0.0002^{\star}$ \\
\hline $5.4-8.3$ & & 1.69 & 0.67 to 4.23 & \\
\hline $8.4-12.7$ & & 3.55 & 1.39 to 9.06 & \\
\hline$\geqslant 12.8$ & & 7.66 & 2.82 to 20.78 & \\
\hline Creatinine $(\mu \mathrm{mol} / \mathrm{l})$ & 237 & & & \\
\hline$\leqslant 83$ & & - & & 0.16 \\
\hline $84-101$ & & 0.80 & 0.34 to 1.87 & \\
\hline $102-147$ & & 1.32 & 0.57 to 3.06 & \\
\hline$\geqslant 148$ & & 2.01 & 0.85 to 4.72 & \\
\hline Alkaline phosphatase (IU/l) & 174 & & & \\
\hline$\leqslant 125$ & & - & & 0.07 \\
\hline $126-200$ & & 0.48 & 0.18 to 1.27 & \\
\hline $201-282$ & & 1.08 & 0.42 to 2.76 & \\
\hline$\geqslant 283$ & & 1.79 & 0.69 to 4.68 & \\
\hline Alanine transaminase $(\mathrm{U} / \mathrm{l})$ & 144 & & & \\
\hline$\leqslant 17$ & & - & & 0.46 \\
\hline $17.1-28.5$ & & 1.70 & 0.63 to 4.62 & \\
\hline $28.6-47.5$ & & 2.34 & 0.78 to 7.04 & \\
\hline$\geqslant 47.6$ & & 1.84 & 0.65 to 5.21 & \\
\hline$\gamma$-glutaryl transaminase $(\mathrm{U} / \mathrm{l})$ & 134 & & & \\
\hline$\leqslant 23$ & & - & & 0.56 \\
\hline $23.1-45.0$ & & 0.49 & 0.17 to 1.44 & \\
\hline $45.1-81.3$ & & 0.62 & 0.21 to 1.84 & \\
\hline$\geqslant 81.4$ & & 0.86 & 0.29 to 2.54 & \\
\hline Albumin (g/l) & 177 & & & \\
\hline$\geqslant 35.6$ & & - & & $0.006^{\star}$ \\
\hline $32.1-35.5$ & & 3.11 & 1.06 to 9.17 & \\
\hline $28.1-32.0$ & & 3.94 & 1.39 to 11.19 & \\
\hline$\leqslant 28.0$ & & 6.73 & 2.28 to 19.83 & \\
\hline Effusion on chest radiograph & 244 & 5.47 & 1.56 to 19.18 & $0.008^{\star}$ \\
\hline $\begin{array}{l}\text { Bilateral shadowing on chest } \\
\text { radiograph }\end{array}$ & 237 & 2.06 & 0.82 to 5.17 & 0.12 \\
\hline
\end{tabular}

of cases or controls receiving intravenous ampicillin, co-amoxiclav or cephalosporin as initial treatment (data not shown). More controls $(70 \%)$ than cases $(52 \%)$ received combination therapy comprising a beta lactam plus macrolide on admission. However, this association was not statistically significant after adjusting for age (odds ratio 0.57 , confidence interval $(\mathrm{CI}) 0.32$ to $1.03, \mathrm{p}=0.06)$.

Table 4 Factors significantly associated with mortality on multivariate analysis

\begin{tabular}{llll}
\hline Clinical feature & Odds ratio & 95\% Confidence interval & p value \\
\hline Age $>65$ years & 6.60 & 2.47 to 17.64 & $<0.001$ \\
Confusion & 4.20 & 1.77 to 9.94 & 0.001 \\
Temperature $<37^{\circ} \mathrm{C}$ & 2.74 & 1.26 to 5.95 & 0.01 \\
$\mathrm{RR}>24$ breaths $/ \mathrm{min}$ & 3.65 & 1.69 to 7.88 & 0.01 \\
Sodium $<135 \mathrm{mmol} / 1$ & 3.09 & 1.29 to 7.39 & 0.01 \\
Urea $>7 \mathrm{mmol} / 1$ & 3.12 & 1.33 to 7.29 & $<0.01$ \\
Effusion on chest radiograph & 6.23 & 1.25 to 30.98 & 0.03 \\
\hline
\end{tabular}

$\mathrm{RR}=$ respiratory rate.
A respiratory pathogen was identified in 13 cases $(11 \%)$ and 15 controls (13\%). Streptococcus pneumoniae was the commonest pathogen isolated (14 patients) and was recovered from blood cultures in four cases and five controls. Haemophilus influenzae was isolated in one case and seven controls while Pseudomonas aeruginosa was isolated in five cases but none of the control patients. Moraxella catarrhalis and Klebsiella sp was isolated from one case and one control, respectively.

SEVERITY ASSESSMENT

Nine of the 26 variables measured at admission were significantly $(\mathrm{p}<0.05)$ associated with mortality after adjusting for age. These were body temperature, respiratory rate, presence of mental confusion, admission from a nursing or residential home, haemoglobin, urea, sodium, albumin, and the presence of an effusion on the chest radiograph (tables 1,2 , and 3 ). The association of haemoglobin with mortality was of borderline significance when analysed as a trend in odds ratio across the four categories and those in the top quartile had no statistically significant increase in mortality relative to those in the lowest quartile. Blood gas tensions were measured in 137 patients, 26 (19\%) of whom were on supplemental oxygen at the time. Neither $\mathrm{PaO}_{2}$ (regardless of $\mathrm{FiO}_{2}$ ) nor the $\mathrm{PaO}_{2} / \mathrm{FiO}_{2}$ ratio was found to be associated with mortality.

Albumin was not included in the multivariate analysis as data were scanty, reflecting the practice in most hospitals of testing serum albumin levels only if clinically indicated. Complete data were therefore available for multivariate analysis in $186(76 \%)$ subjects. There was no difference in the proportion of cases or controls with complete data.

Age, mental confusion, and presence of a pleural effusion remained significantly $(p \leqslant 0.02)$ associated with mortality when analysed as four level factors while the association of temperature, respiratory rate, and sodium with mortality was of borderline significance $(p \leqslant 0.06)$. In the final model, with continuous variables re-categorised as binary variables, age over 65 years, the presence of confusion, temperature $<37^{\circ} \mathrm{C}$, respiratory rate $>24$ breaths $/ \mathrm{min}$, urea $>7 \mathrm{mmol} / 1$, sodium $<135 \mathrm{mmol} / \mathrm{l}$, and the presence of an effusion on the chest radiograph were all found to be independently associated with mortality (table 4). The risk estimates obtained using a respiratory rate of $\geqslant 30$ breaths/min as a cut off value (as in the BTSr and mBTSr) were also examined. The resulting odds ratios were marginally smaller for all predictors of mortality (data not shown).

\section{SEVERITY PREDICTION RULES}

Of the factors included in the BTSr, missing data were most evident for respiratory rate which was recorded in $99(81 \%)$ cases and 97 $(80 \%)$ controls. The BTSr had a sensitivity of $52 \%$ and specificity of $79 \%$ in predicting mortality compared with a sensitivity of $66 \%$ and specificity of $73 \%$ for the mBTSr (table 5 ). 
Table 5 Comparison of three severity rules in predicting death from community acquired pneumonia in 188 patients with complete data*

\begin{tabular}{|c|c|c|}
\hline Severity prediction rule & Sensitivity (\%) & Specificity (\%) \\
\hline BTS rule & 52 & 79 \\
\hline Modified BTS rule & 66 & 73 \\
\hline Risk class $V^{\star \star}$ & 44 & 85 \\
\hline \multicolumn{3}{|l|}{ Derivation studies: } \\
\hline BTS rule & 88 & 79 \\
\hline Modified BTS rule & 95 & 71 \\
\hline
\end{tabular}

^Based on $188(77 \%)$ patients for whom complete data for respiratory rate, urea, diastolic blood pressure, and presence of confusion was available. ${ }^{\star \star}$ Where data were missing, these were taken to be within the normal range. This may have led to underestimation of severity in some patients.

In order to assess the effect of missing values on the performance of the prediction rules, we assumed that all missing values for the respiratory rate in cases were $\geqslant 30$ breaths $/ \mathrm{min}$ and that all missing values for respiratory rate in controls were $<30$ breaths $/ \mathrm{min}$. With this correction the sensitivities of the BTS and mBTS rules were still only $58 \%$ and $73 \%$, respectively.

Application of the PSI showed that none of the cases was assigned to risk class I although 20 cases $(16 \%)$ were in risk classes II and III combined (fig 1). Using risk class $\mathrm{V}$ to predict patients at high risk of death had a sensitivity of $44 \%$ and a specificity of $85 \%$ (table 5 ).

\section{Discussion}

We have identified six independent predictors of mortality apart from age. Three of these (raised respiratory rate, raised urea concentration, and presence of mental confusion) form part of the mBTSr.

RESPIRATORY RATE

A raised respiratory rate has consistently been shown to be significantly associated with mortality. ${ }^{3}{ }^{7-12}$ In clinical practice a respiratory rate of $\geqslant 30$ breaths/min is commonly taken as the threshold indicative of a poor prognosis. However, from our data a respiratory rate of $>24$ breaths/min was a marginally better predictor of mortality with a plateau effect suggested at rates above 24 breaths/min. This contrasts with the finding of van Eeden et al, based on 34 subjects, of a linear association of respiratory rate with mortality. ${ }^{13}$

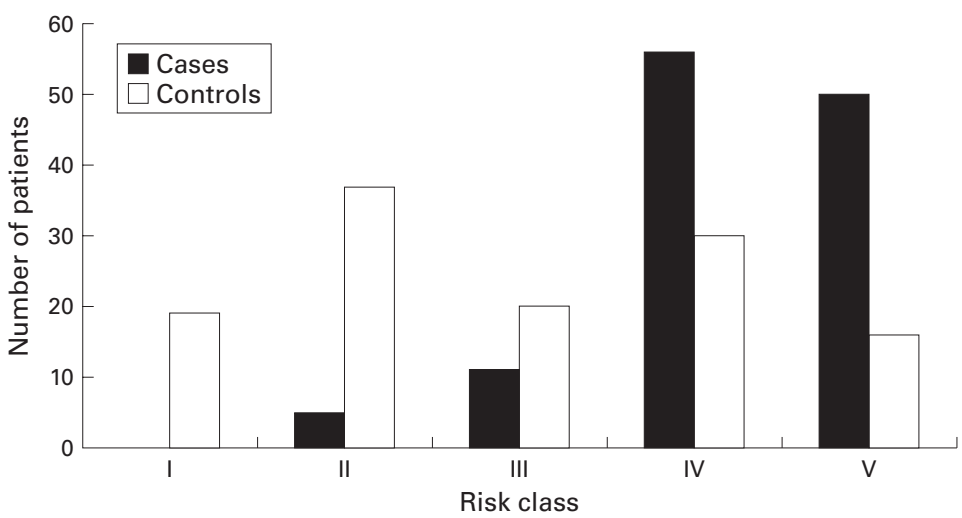

Figure 1 Classification of cases and controls according to the pneumonia severity index (PSI). Where data for the computation of the PSI score were missing they were taken to be within the normal range.
BLOOD UREA

Apart from this study, only two other studies have identified a concentration of urea of $>7 \mathrm{mmol} / \mathrm{l}$ as an independent predictor of mortality; both had upper age limits. ${ }^{28}$ Ours is the first study to include a full age range (16-98 years) that has confirmed the value of blood urea concentration of $>7 \mathrm{mmol} / \mathrm{l}$ on hospital admission as a predictor of mortality. Whether a higher level of urea may need to be used in the very old, as described by Janssens et al, remains unclear. ${ }^{14}$

ALTERED MENTAL STATE

Our study corroborates work from North America showing that new or altered mental status on hospital admission is independently predictive of mortality. ${ }^{45}$ Unfortunately, the retrospective design of our study precluded the use of strict objective criteria for the diagnosis of mental confusion. Use of the abbreviated mental test score $^{16}$ as a tool for detecting confusion in patients with $\mathrm{CAP}^{3}$ is currently being tested by us.

\section{TEMPERATURE}

Compared with younger patients, a lack of pyrexia in elderly patients admitted to hospital with CAP has been shown to be more common and to be a risk factor for mortality. This may reflect the decreased immune response to infection reported in older patients..$^{914}{ }^{17-19}$ Our finding that a low body temperature $\left(<37^{\circ} \mathrm{C}\right)$ on hospital admission was strongly predictive of mortality in CAP may therefore be related to the proportion of elderly patients in our study ( $48 \%$ were aged $\geqslant 75$ years)

SODIUM

A low sodium concentration $(<130 \mathrm{mmol} / \mathrm{l})$ has previously been reported to be a predictor of mortality in CAP by Fine et al and forms part of the present PSI. ${ }^{20}$ Although the mechanism of hyponatraemia in acute pneumonia remains unclear, there is some evidence to implicate a latent vasopressin dependent impairment of water excretion which is related to the extent of radiographic shadowing. ${ }^{21}$

PLEURAL EFFUSION

In their prospective study of radiographic features in CAP Hasley et al reported that only the presence of bilateral effusions was of prognostic significance. ${ }^{22}$ Our finding that an effusion on the chest radiograph is associated with mortality is in agreement with this. However, being based on only 15 cases and five controls, we feel that this observation requires confirmation before any clinical significance can be attached to it.

ADMISSION FROM A NURSING OR RESIDENTIAL

HOME

To our knowledge, this is the first UK study to examine the contribution of admission from a nursing or residential home to prognosis. Although an association with mortality was found after adjustment for age, this did not remain following multivariate analysis. In contrast, studies conducted in North America have identified nursing home residence as an 
independent predictor of mortality. ${ }^{12}$ International differences in nursing home facilities may account for these discrepant findings.

\section{SEVERITY PREDICTION RULES}

When applied to our data, the BTS rule predicted mortality with $52 \%$ sensitivity and $79 \%$ specificity while the modified BTS rule was more sensitive $(66 \%)$ but marginally less specific $(73 \%)$. The specificities of these rules are comparable to results from the two derivation studies but the decreased sensitivities were unexpected (BTS rule: sensitivity $88 \%$, specificity $79 \%$; mBTS rule: sensitivity $95 \%$, specificity $71 \%$ ).

This difference in sensitivity may be due to the relatively large proportion of elderly patients in our study ( $48 \%$ aged $\geqslant 75$ years) which reflects the age profile of patients admitted as emergencies with CAP in our age integrated medical service in the UK. ${ }^{1}$ This suggestion is supported by a recent retrospective study of 1356 patients aged $\geqslant 65$ years conducted in the USA where the BTS rule was found to have a sensitivity of only $50.3 \%$ and a specificity of $70.3 \% .^{23}$

The PSI has been advocated as a means of stratifying patients into five risk classes according to their risk of mortality. Whether different management strategies can be related to these risk classes remains to be determined. ${ }^{24}$ In our study a score of $>130$ (risk class V) was $85 \%$ specific in predicting mortality but only $44 \%$ sensitive. At present, therefore, there appears to be no advantage in using PSI risk class $\mathrm{V}$ to predict mortality compared with the BTS and mBTS rules which are both much simpler to use.

The main weakness of our study is its retrospective design. Collection of some data was therefore incomplete. This was most marked for tests which, in many UK hospitals, are only performed when there is a clinical suspicion that they may be abnormal. These included liver function tests, blood glucose, and blood gas tensions. However, the proportion of missing data was similar for both cases and controls and results were not significantly different when analyses were performed assuming missing values to be normal (data not shown). Importantly, in contrast with many other studies, enough outcome events relative to the number of independent variables examined using multivariate analysis were included (a minimum of 10 outcome events for each independent variable has been recommended). ${ }^{25}$ Avoidance of overfitting is reflected in the narrow confidence intervals for risk estimates obtained.

\section{CONCLUSION}

We have confirmed the predictive values of three of the four factors included in the MBTS severity rule and the specificities of the BTS and mBTS rules in predicting mortality in patients in the UK with CAP. However, in our study, which included a large proportion of elderly patients, these rules were not shown to be as sensitive as reported in the derivation studies. We therefore have concerns about the use of these rules in the elderly, particularly those aged $\geqslant 75$ years, as a reliable indicator of those who do not have severe pneumonia. A study of severity factors for this older age group is the subject of a separate analysis. We advocate the need for a UK prospective validation study specifically addressing the issue of the elderly patient with CAP using well defined criteria for the diagnosis of mental confusion. In the meantime, the application of these severity prediction rules in clinical practice should be tempered by sound clinical judgement.

Funding: This project was funded by a research grant from Hoechst Marion Roussel.

1 Guest JF, Morris A. Community acquired pneumonia: the annual cost to the National Health Service in the UK. Eur Respir F 1997; 10:1530-4.

Respir F 1997;10:1530-4.
2 Anonymous. Community-acquired pneumonia in adults in British hospitals in 1982-1983: a survey of aetiology, mortality, prognostic factors and outcome. The British Thoracic Society and the Public Health Laboratory

Service. $Q \mathcal{F} M$ Med 1987;62:195-220.
3 Neill AM, Martin IR, Weir R, et al. Community acquired pneumonia: aetiology and usefulness of severity criteria on admission. Thorax 1996;51:1010-6.

4 Fine MJ, Auble TE, Yealy DM, et al. A prediction rule to identify low-risk patients with community-acquired pneumonia. N Engl f Med 1997;336:243-50.

5 Wasson JH, Sox HC, Neff RK, et al. Clinical prediction rules. Applications and methodological standards. N Engl $\mathcal{F}$ Med 1985;313:793-9.

6 Selker HP. Criteria for adoption in practice of medical practice guidelines. Am F Cardiol 1993;71:339-41.

7 Moore M, Onorato IM, McCray E, et al. Trends in Moore M, Onorato IM, McCray E, et al. Trends in
drug-resistant tuberculosis in the United States, 1993drug-resistant tuberculosis in
1996. $A M A$ 1997;278:833-7.

8 Farr BM, Sloman AJ, Fisch MJ. Predicting death in patients hospitalized for community-acquired pneumonia. Ann Intern Med 1991;115:428-36.

9 Riquelme R, Torres A, El-Ebiary M, et al. Communityacquired pneumonia in the elderly: a multivariate analysis of risk and prognostic factors. Am $\mathcal{F}$ Respir Crit Care Med 1996;154:1450-5.

10 Fine MJ, Smith MA, Carson CA, et al. Prognosis and outcomes of patients with community-acquired pneumonia. A meta-analysis. FAMA 1996;275:134-41.

11 Ortqvist A, Hedlund J, Grillner L, et al. Aetiology, outcome and prognostic factors in community-acquired pneumonia requiring hospitalization. Eur Respir F 1990;3:1 105-13.

12 Marrie TJ, Durant H, Yates L. Community-acquired pneumonia requiring hospitalization: 5-year prospective study. monia requiring hospitalization:
Rev Infect Dis 1989;11:586-99.

13 van Eeden SF, Coetzee AR, Joubert JR. Communityacquired pneumonia: factors influencing intensive care acquired pneumonia: factors influencing

14 Janssens JP, Gauthey L, Herrmann F, et al. Communityacquired pneumonia in older patients. I Am Geriatr Soc $1996 ; 44: 539-44$

15 Fine MJ, Singer DE, Hanusa $\mathrm{BH}$, et al. Validation of a pneumonia prognostic index using the MedisGroups comparative hospital database. Am F Med 1993;94:153-9.

16 Qureshi KN, Hodkinson HM. Evaluation of a ten-question mental test in the institutionalized elderly. Age Ageing 1974;3:152-7.

17 Marrie TJ, Haldane EV, Faulkner RS, et al. Communityacquired pneumonia requiring hospitalization. Is it different in the elderly? $\mathcal{F}$ Am Geriatr Soc 1985;33:671-80.

18 Venkatesan P, Gladman J, Macfarlane JT, et al. A hospital study of community acquired pneumonia in the elderly. Thorax 1990;45:254-8.

19 Schneider EL. Infectious diseases in the elderly. Ann Intern Med 1983;98:395-400

20 Fine MJ, Hanusa BH, Lave JR, et al. Comparison of a disease-specific and a generic severity of illness measure for patients with community-acquired pneumonia. $\mathcal{F}$ Gen patients with community-acd
Intern Med 1995;10:359-68.

21 Dreyfuss D, Leviel F, Paillard M, et al. Acute infectious pneumonia is accompanied by a latent vasopressindependent impairment of renal water excretion. Am Rev Respir Dis 1988;138:583-9.

22 Hasley PB, Albaum MN, Li YH, et al. Do pulmonary radiographic findings at presentation predict mortality in patients with community-acquired pneumonia? Arch Intern Med 1996;156:2206-12.

23 Conte HA, Chen YT, Mehal W, et al. A prognostic rule for elderly patients admitted with community-acquired pneumonia. Am F Med 1999;106:20-8.

2424 Atlas SJ, Benzer TI, Borowsky LH, et al. Safely increasing the proportion of patients with community-acquired pneumonia treated as outpatients: an interventional trial. pneumonia treated as outpatients:

25 Concato J, Feinstein AR, Holford TR. The risk of determining risk with multivariable models. Ann Intern Med 1993;118:201-10. 